\title{
Dalbavancin Use in Vulnerable Patients Receiving Outpatient Parenteral Antibiotic Therapy for Invasive Gram-Positive Infections
}

\author{
Jacqueline T. Bork - Emily L. Heil - Shanna Berry · Eurides Lopes · \\ Rohini Davé · Bruce L. Gilliam • Anthony Amoroso
}

Received: March 9, 2019 / Published online: May 3, 2019

(C) The Author(s) 2019

\begin{abstract}
Introduction: Dalbavancin is approved for acute bacterial skin and skin structure infections (ABSSSIs) but offers a potential treatment option for complicated invasive gram-positive infections. Importantly, dalbavancin's real benefits may be in treating complicated infections in vulnerable patient populations, such as persons who inject drugs (PWID).

Methods: A multicenter retrospective analysis was performed from March 2014 to April 2017 to assess 30- and 90-day clinical cure and adverse drug events (ADEs) in adult patients
\end{abstract}

Enhanced digital features To view enhanced digital features for this article go to https://doi.org/10.6084/ m9.figshare.8006438.

J. T. Bork $(\bowtie) \cdot$ S. Berry · E. Lopes ·

B. L. Gilliam - A. Amoroso

Division of Infectious Disease, Department of

Medicine, University of Maryland School of

Medicine, Baltimore, MD, USA

e-mail: jabork@som.umaryland.edu

E. L. Heil

University of Maryland School of Pharmacy,

Baltimore, MD, USA

R. Davé

Department of Pharmacy, VA Maryland Health Care

System, Baltimore, MD, USA

J. T. Bork · A. Amoroso

Department of Medicine, VA Maryland Health Care

System, Baltimore, MD, USA who received $\geq 1$ dose of dalbavancin for a non-ABSSSI indication.

Results: During the study period, 45 patients received dalbavancin, 28 for a non-ABSSSI indication. The predominant infections treated included osteomyelitis (46\%), endovascular infection (25\%) and uncomplicated bacteremia (14\%). Half of the patients had positive Staphylococcus aureus in cultures, 29\% methicillin resistant and $21 \%$ methicillin susceptible. Most patients were prescribed dalbavancin as sequential treatment with a median of 13.5 days of prior antibiotic therapy. The most common reason for choosing dalbavancin over standard therapy use was PWID (54\%). Seven patients were lost to follow-up at day 30. Of the remaining evaluable patients, 30-day clinical cure was achieved in 15/21 (71\%) patients. The most common reason for failure was lack of source control $(4 / 6,67 \%)$. At day 90 , relapse occurred in two patients. Three patients had a potential dalbavancin-associated ADE: two patients with renal dysfunction and one patient with pruritus.

Conclusions: This study demonstrates a possible role for dalbavancin in the treatment of non-ABSSSI invasive gram-positive infections in select vulnerable OPAT patients.

Keywords: Dalbavancin; Outpatient parenteral antibiotic therapy; Substance use disorder 


\section{INTRODUCTION}

Invasive gram-positive infections, particularly those caused by methicillin-resistant Staphylococcus aureus (MRSA), are a therapeutic challenge and significant burden on the health care system [1-3]. Often, optimal treatment requires long-term intravenous antibiotic therapy, which poses a particular challenge for treating patients classified as vulnerable or high-risk for complications such as persons who inject drugs (PWID) or those who lack social support such as the elderly, homeless or patients with an underlying psychiatric illness [4, 5]. These patients are at higher risk for drug-related adverse events (ADEs), line-associated complications, nonadherence and hospital re-admission $[6,7]$.

Dalbavancin, a novel second-generation lipoglycopeptide antibiotic with an extended half-life was approved by the Food and Drug Administration in 2014 for acute gram-positive bacterial soft tissue and skin structure infections (ABSSSIs). Dalbavancin's half-life of approximately 14 days has the potential to obviate the need for long-term intravenous access [8].

There are limited data on the use of dalbavancin for indications other than 1-2 doses for treatment of ABSSSI. Case reports have demonstrated success in treating more complicated infections such as MRSA pneumonia, osteomyelitis and endovascular infections [9-11]. Dalbavancin for treatment of catheterrelated bloodstream infections demonstrated efficacy in a small phase 2 open-label study with overall success of $87 \%$ (95\% CI 73.2-100\%) [12]. Recently, a randomized control trial for dalbavancin in the treatment of osteomyelitis versus standard of care demonstrated clinical efficacy with overall success of $97 \% \quad(95 \% \quad \mathrm{CI}$ 89.6-99.6\%) [13]. In addition, both studies demonstrated safety with mild ADEs that were similar to comparators.

Herein, we describe characteristics and outcomes of off-label use of dalbavancin for invasive gram-positive infections as primarily sequential treatment in patients with high risk for complications.

\section{METHODS}

\section{Study Location, Design and Eligibility}

The study was conducted at the University of Maryland Medical Center (UMMC), a 750-bed acute tertiary care center in Baltimore, $\mathrm{MD}$, and the VA Maryland Health Care System (VAMHCS), an acute care facility comprised of a 137-bed inpatient unit and 2 long-term care facilities. Patients were identified from the Antibiotic Stewardship Program clinical management database at UMMC and from the outpatient parenteral antibiotic therapy (OPAT) program at the VAMHCS. All adult patients who received at least one dose of dalbavancin for a non-ABSSSI indication between March 2014 and April 2017 were included in the review. During this study period, all dalbavancin prescriptions were made at the clinical discretion of the Infectious Diseases (ID) physicians evaluating the patient.

\section{Data Extraction and Definitions}

Charts were primarily reviewed by one reviewer and adjudicated by the research team, consisting of three ID physicians and two ID pharmacists. Charts were abstracted for patient characteristics (demographics, comorbidities, length of hospital stay), infection characteristics (type of infection, microbiologic data) and treatment characteristics (indication for dalbavancin, prior antibiotic received, number of doses of dalbavancin). Type of infection was defined by the ID physician at the bedside. Each case was probed for the exact reason for dalbavancin over standard therapy, which included: PWID, any history of substance use (drug use by any route and alcohol abuse), homelessness, lack of home support, and patient refusal for intravenous access or institutional placement.

The primary outcome was the proportion of patients with defined clinical cure 30 days after completion of the planned dalbavancin course (i.e., end date), termed "30-day clinical cure." Secondary outcomes included the proportion of patients without recurrent or persistent infection 90 days after completion of planned 
dalbavancin, termed "90-day clinical cure," and ADEs.

Clinical cure was defined as a composite of the following factors: resolution of clinical signs of infection (erythema, swelling, pain), absence of fever, normalization of inflammatory markers (C-reactive protein, erythrocyte sedimentation rate), normalization of the white count, source control defined as removal or drainage of the foci of infection, resolution of radiographic signs of infection and/or microbiologic clearance of organisms. If there was readmission to the hospital for infection, clinical failure was assumed regardless of the above factors.

Patients who did not meet criteria for clinical cure were defined as clinical failure and further characterized as failure due to one of the following: (1) death, (2) intolerance or adverse event, (3) lack of access to subsequent dalbavancin, (4) lack of source control and (5) worsening signs of infection or relapse infection. Lack of source control was defined based on retained hardware or device, surgical margins that were not clear, positive cultures from a proximal specimen or undrained abscess.

Adverse events were defined as any untoward experience that was likely to be associated with dalbavancin based on the specific ADE and temporal relationship with dalbavancin.

\section{Data Analysis}

Descriptive statistics were performed for all data in total for both facilities. Outcome analysis for 30-day clinical cure and 90-day clinical cure was evaluated in total on an "as-treated" basis, excluding patients lost to follow-up. In addition, an "intention-to-treat" analysis for 30- and 90-day clinical cure for each infection type was also performed, including patients lost to follow-up. All analyses were performed using Microsoft Excel software (Redmond, WA).

The study was approved with a waiver of informed consent in an expedited review by the University of Maryland, Baltimore, Institutional Review Board, which oversees both UMMC and VAMHCS facilities. This study was also performed in accordance with the 1964 Helsinki
Declaration and its later amendments or comparable ethical standards.

\section{RESULTS}

A total of 45 patients received dalbavancin at UMMC and VAMHCS from March 2014 to March 2017. Twenty-eight patients met the inclusion criteria for further review (Fig. 1). Table 1 describes the overall patient characteristics. Most patients were male, and the median age was 52 years old. Underlying substance use disorder (SUD) (68\%) was the most common comorbidity followed by hepatitis C (25\%) and diabetes mellitus (21\%). The most common indications for antibiotics included osteomyelitis (46\%), endovascular infection (25\%) and uncomplicated bacteremia (14\%). PWID (54\%) was the predominant reason for dalbavancin (over standard therapy) followed by patient refusal of long-term intravenous access $(25 \%)$. Dalbavancin was initiated in 22 patients (79\%) in the inpatient and 6 patients (21\%) in the outpatient setting. The median number of doses, including loading doses, in total was three. Median duration of prior antibiotic was 13.5 days. Sixty-eight percent $(19 / 28)$ were on prior antibiotics for 1 week or longer before switching to dalbavancin. Twenty-eight percent (8/28) had completed $\geq 50 \%$ of the therapy prior to dalbavancin.

MRSA and mixed gram-positive organisms were the most common cultures targeted followed by methicillin-susceptible $S$. aureus (MSSA) and coagulase-negative staphylococci (CoNS) (Table 1). Mixed gram-positive organisms included Enterococcus faecalis, MRSA, MSSA and CoNS. One patient had Propionibacterium acnes isolated. In six patients, dalbavancin was used in combination with an oral fluoroquinolone to treat a concomitant gram-negative organism, three of which were for definitive therapy against Pseudomonas aeruginosa $(n=2)$ and Escherichia coli $(n=1)$, in addition to one requiring oral metronidazole to cover Bacteroides fragilis. In the remaining three patients, an oral fluoroquinolone was used as part of empiric therapy. 


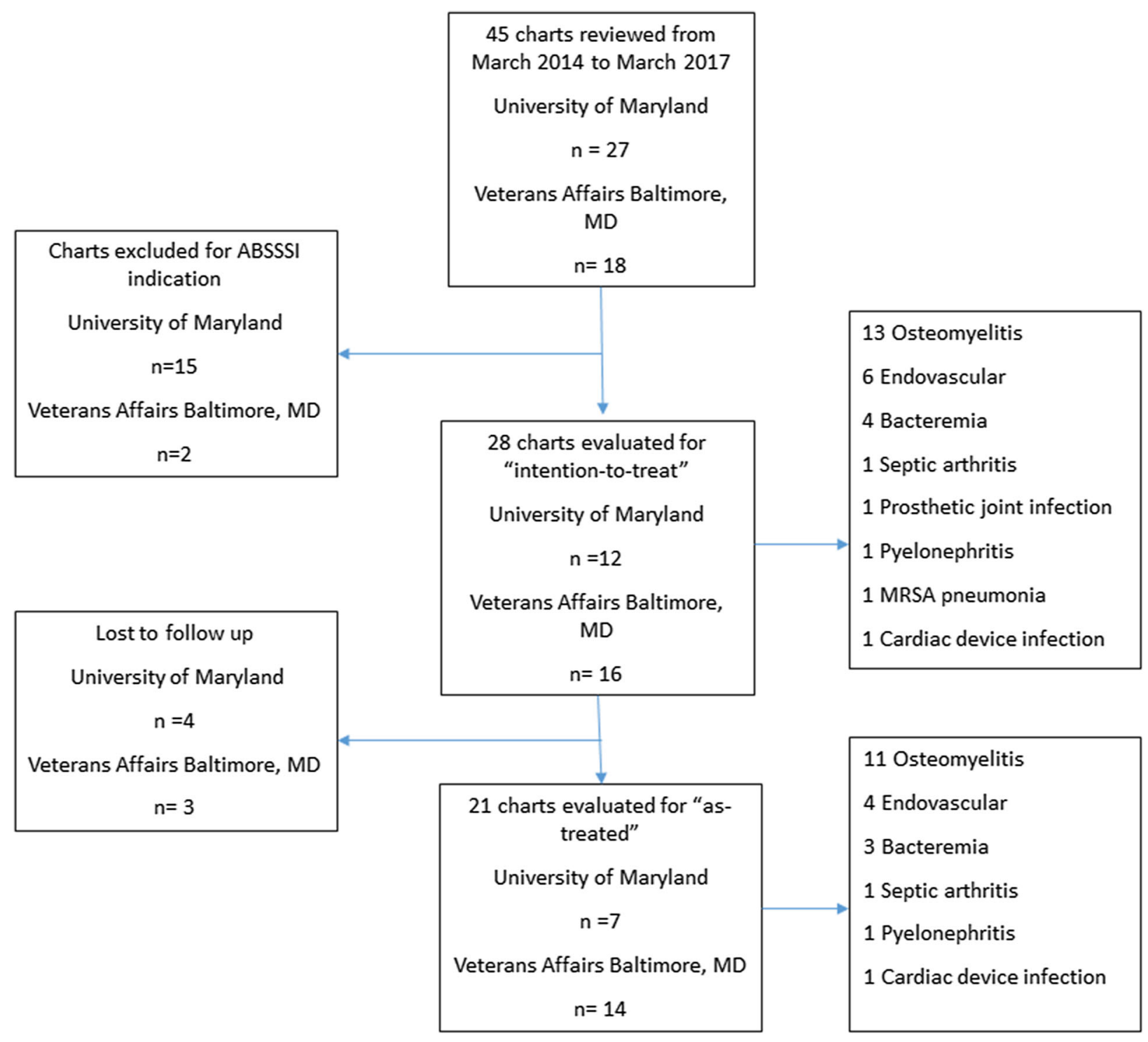

Fig. 1 Patient selection. ABSSSI acute bacterial skin and skin structure infections

\section{Outcomes}

Twenty-eight patients received off-label use of dalbavancin for an invasive gram-positive infection. The "as-treated" analysis included 21 patients and excluded 7 patients who were lost to follow-up at the 30-day outcome. Outcomes are presented in Table 2 . There were 15 patients (71\%) with clinical cure at day 30 . The most common reason for failure was lack of source control $(4 / 6,67 \%)$. Of the 15 patients who had clinical cure at day 30,2 (one with pyelonephritis and one with cardiac-device infection) had relapse of infection, both due to lack of source control prior to 90 days. The patient with pyelonephritis had recrudescent infection with CoNS with evidence of a retained stone that was later removed. The patient with cardiac-device infection had debridement with cultures revealing CoNS and Corynebacterium spp. He went on to receive an extended course of intravenous daptomycin due to retained cardiac wires.

The "intention-to-treat" 30- and 90-day clinical cure analysis included all 28 patients 
Table 1 Patient characteristics

\begin{tabular}{|c|c|c|c|}
\hline & $\begin{array}{l}\text { UMMC } \\
(\%)\end{array}$ & $\begin{array}{l}\text { VAMHCS } \\
(\%)\end{array}$ & $\begin{array}{l}\text { Total } \\
(\%)\end{array}$ \\
\hline Total $n$ & 12 & 16 & 28 \\
\hline $\begin{array}{l}\text { Median age (years, } \\
\text { IQR) }\end{array}$ & 39.5 & 59.5 & $\begin{array}{l}52 \\
(21.5)\end{array}$ \\
\hline Male & $10(83)$ & $16(100)$ & $26(93)$ \\
\hline \multicolumn{4}{|l|}{ Comorbidities } \\
\hline Substance abuse & $9(75)$ & $10(63)$ & $19(68)$ \\
\hline $\mathrm{DM}$ & $0(0)$ & $6(40)$ & $6(21)$ \\
\hline Hepatitis C & $4(33)$ & $3(19)$ & $7(25)$ \\
\hline Vascular & $0(0)$ & $4(25)$ & $4(14)$ \\
\hline Cardiovascular & $1(8)$ & $3(19)$ & $4(14)$ \\
\hline Malignancy & $1(8)$ & $1(6)$ & $2(7)$ \\
\hline CKD & $0(0)$ & $2(13)$ & $2(7)$ \\
\hline HIV & $0(0)$ & $1(6)$ & $1(4)$ \\
\hline \multicolumn{4}{|l|}{ Infection } \\
\hline Osteomyelitis & $3(25)$ & $10(63)$ & $13(46)$ \\
\hline Endovascular & $4(33)$ & $2(13)$ & $6(21)$ \\
\hline Bacteremia & $3(25)$ & $1(6)$ & $4(14)$ \\
\hline Other $^{\mathbf{a}}$ & $2(17)$ & $3(19)$ & $5(18)$ \\
\hline \multicolumn{4}{|l|}{ Culture } \\
\hline MRSA & $6(50)$ & $2(13)$ & $8(29)$ \\
\hline MSSA & $3(25)$ & $3(19)$ & $6(21)$ \\
\hline CoNS & $1(8)$ & $3(19)$ & $4(14)$ \\
\hline Mixed GPO & $0(0)$ & $8(50)$ & $8(29)$ \\
\hline Not available & $2(17)$ & $3(19)$ & $5(18)$ \\
\hline \multicolumn{4}{|l|}{$\begin{array}{l}\text { Reason for } \\
\text { dalbavancin }\end{array}$} \\
\hline PWID & $9(75)$ & $7(44)$ & $16(57)$ \\
\hline $\begin{array}{l}\text { Patient refusal of } \\
\text { PICC }\end{array}$ & $2(17)$ & $2(13)$ & $4(14)$ \\
\hline Other ${ }^{\mathbf{b}}$ & $1(8)$ & $5(31)$ & $6(21)$ \\
\hline Substance use ${ }^{c}$ & $0(0)$ & $2(13)$ & $2(7)$ \\
\hline
\end{tabular}

Table 1 continued

\begin{tabular}{llll}
\hline & $\begin{array}{l}\text { UMMC } \\
(\%)\end{array}$ & $\begin{array}{l}\text { VAMHCS } \\
(\%)\end{array}$ & $\begin{array}{l}\text { Total } \\
(\%)\end{array}$ \\
\hline $\begin{array}{l}\text { Location of initiation } \\
\text { of dalbavancin }\end{array}$ & & & \\
$\begin{array}{l}\text { Inpatient } \\
\text { Outpatient }\end{array}$ & $11(92)$ & $11(69)$ & $22(79)$ \\
$\begin{array}{l}\text { Median dalbavancin } \\
\text { doses (IQR) }\end{array}$ & 1.5 & 5.5 & $6(21)$ \\
$\begin{array}{l}\text { Median LOPA } \\
\text { (days, IQR) }\end{array}$ & 9 & 15 & 13.5 \\
$\begin{array}{l}\text { Median LOS (days, } \\
\text { IQR) }\end{array}$ & 10 & 7 & $8(12.5)$ \\
\hline
\end{tabular}

VAMHCS VA Maryland Health Care System, UMMC University of Maryland Medical Center, $D M$ diabetes mellitus, $H I V$ human immunodeficiency virus, $C K D$ chronic kidney disease, MSSA methicillin susceptible $S$. aureus, MRSA methicillin-resistant $S$. aureus, CoNS coagulase-negative staphylococcus, GPO gram-positive organisms, PWID persons who inject drugs, LOPA length of prior antibiotic, $L O S$ length of stay

a MRSA pneumonia, septic arthritis, prosthetic joint infection, cardiac device infection, pyelonephritis

b Lack of home support, homelessness, not documented

${ }^{c}$ Non-injectable substance

Table 2 As-treated outcomes for all indications

\section{UMMC (\%) VAMHCS (\%) Total (\%)}

30 days

$\begin{array}{llrr}\text { Follow-up } & 7(58) & 14(88) & 21(75) \\ \text { Cure } & 5(71) & 10(71) & 15(71) \\ \text { Failure } & 2(29) & 4(29) & 6(29)\end{array}$

Adverse events ${ }^{\mathrm{a}}$

\begin{tabular}{llll} 
Renal & $1(14)$ & $1(7)$ & $2(10)$ \\
Pruritus & $1(14)$ & $0(0)$ & $1(5)$ \\
\hline
\end{tabular}

${ }^{\text {a }}$ Of total patients evaluable at day 30

stratified by infection type. Outcomes for each infection are presented in Fig. 2. Thirteen patients were treated for osteomyelitis with a 30 -day clinical cure rate of $46 \%(6 / 13)$. Of the 


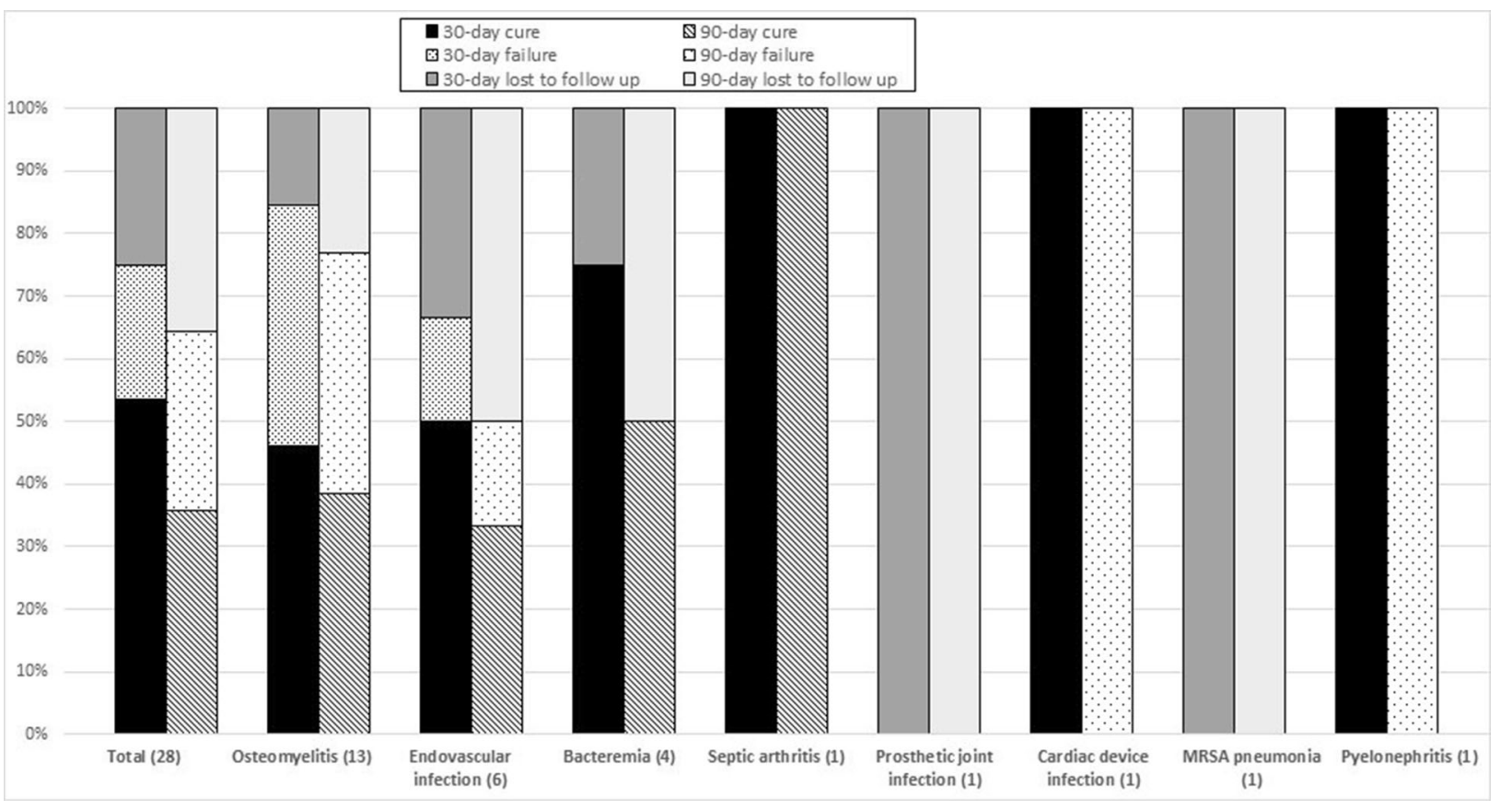

Fig. 2 Intention-to-treat outcomes by indication. $M R S A$ methicillin-resistant $S$. aureus

five failures, four were considered to be due to lack of source control and one due to lack of access to subsequent dalbavancin. All 30-day failures continued on to 90-day failures, including one patient without source control who failed at 90 days because of an unrelated death. There were no additional failures at 90 days; however, three additional patients were lost to follow-up. Six patients were treated for endovascular infections with a 30-day clinical cure rate of $50 \%(3 / 6)$. The one failure was due to possible ADE secondary to acute kidney injury (AKI). Four patients were treated for uncomplicated bacteremia with a 30-day clinical cure of $75 \%(3 / 4)$. There was one patient within each infection type for septic arthritis, pyelonephritis and cardiac device infection with 100\% 30-day clinical cure. The patients with a prosthetic joint infection and MRSA pneumonia could not be evaluated because of loss to follow-up, but they both received all planned doses of dalbavancin via home infusion and infusion clinic, respectively.

Seven (25\%) patients were lost to follow-up at 30 days. Only $1 / 7$ (14\%) patients failed to complete the intended course of therapy, receiving one out of four of the intended doses. The remaining patients either completed therapy while inpatient $(n=3)$ or completed therapy as an outpatient with home infusions $(n=3)$. Six of the 7 patients with loss to followup were patients with SUD, and 6/19 (32\%) of patients with SUD were lost to follow-up. Of the patients with SUD who were followed up, 10/13 $(77 \%)$ had clinical cure at day 30.

There were 3/21 (14\%) patients with a documented ADE. Two patients had AKI that developed subsequent to dalbavancin administration. The first patient, treated with dalbavancin for osteomyelitis, was a 72-year-old male with multiple cardiac comorbidities (coronary artery disease, peripheral vascular disease, cardiomyopathy) including chronic kidney disease with creatinine $1.68 \mathrm{mg} / \mathrm{dl}$ prior to dalbavancin. After one administered dose of dalbavancin at $1000 \mathrm{mg}$, his creatinine increased by $10 \%$, and the decision was made to hold any further dalbavancin doses. Despite holding dalbavancin, his creatinine continued to rise (peaked at $2.5 \mathrm{mg} / \mathrm{dl}$ ), and AKI was considered multifactorial, but most likely secondary to diuresis and/or cardiorenal syndrome. The patient ultimately 
died from decompensated heart failure. The second patient was a 36-year-old pregnant female treated with dalbavancin for an endovascular infection. AKI developed subsequent to the third dose of dalbavancin, a 500-mg continuation dose. The creatinine increased by $50 \%$ from baseline and continued to rise after discontinuation of dalbavancin. The patient underwent renal biopsy for her progressive renal failure and was found to have acute tubular necrosis secondary to IgA nephropathy. The third patient, treated for osteomyelitis, reported generalized pruritus and rash immediately after he finished the first dalbavancin infusion.

\section{DISCUSSION}

This study evaluated clinical outcomes of dalbavancin use for non-ABSSI indications in two different medical centers with high prevalence of SUD (68\%). Dalbavancin successfully treated $15 / 28$ of patients with invasive gram-positive infections, though 7 patients were lost to follow-up, conferring a $71 \%(15 / 21)$ success rate in the treatment of evaluable patients.

There is significant interest in the use of dalbavancin for off-label indications. Dalbavancin offers the potential for line-sparing treatment, which can facilitate outpatient treatment of serious infections, enable hospital discharge for patients disqualified from facility placement and long-term intravenous access due to active substance use, and prevent linerelated complications. Several published case reports demonstrate clinical success of dalbavancin for off-label indications including the treatment of septic phlebitis with secondary MRSA bacteremia, MRSA pneumonia and $\mathrm{Co}$ rynebacterium striatum native septic arthritis $[9,10,14]$. Most recently, larger case series and comparative studies have been published and are described in Table 3. Dalbavancin treatment success ranged from 71 to $92 \%$, but populations and infectious syndromes were fairly heterogenous [12, 13, 15-20]. For comparison, daptomycin real-world experience from a large registry of 6075 patients and mixed infection revealed a clinical success of $81 \%$ [21].
There are published failures and shortcomings of dalbavancin. In one case report, dalbavancin was used for MRSA endocarditis, which resulted in infection relapse and breakthrough bacteremia with vancomycin-intermediate $S$. aureus (VISA) [22]. The development of VISA was thought to be related to sub-inhibitory dalbavancin exposure and high inoculum infection. Comparatively, in vitro studies have demonstrated increased MICs of $S$. aureus and CoNS in the presence of sub-inhibitory dalbavancin [23]. It is unclear how this translates to clinical use of dalbavancin, specifically if dosing strategies should be revised based on etiology, but further studies are needed to evaluate the risk of relapse infection in high inoculum infections.

Osteomyelitis was the most common infection type encountered in our study with the lowest 30-day clinical cure (46\%), equally owing to the poor follow-up and failures. Lack of source control was the primary reason for failure, as documented by persistently positive margins, wound dehiscence and persistent elevation of inflammatory markers. Dalbavancin has been shown to have high concentrations through day 14 in bone in rat studies, which is promising for clinical application [11]. Rappo et al. performed a randomized clinical trial of dalbavancin in first-episode osteomyelitis treatment and found that patients treated with dalbavancin (1500 mg, 2 doses 1 week apart) had clinical cure at day 42 in 65/67 (97\%) versus $7 / 8(88 \%)$ in standard-of-care patients [13]. These are encouraging data for expanding options for treating osteomyelitis. However, this study had few patients with diabetes mellitus in the dalbavancin group (14.3\%) and no patients with underlying substance use disorder. Furthermore, all patients had some degree of debridement. The outcomes of our study suggest that dalbavancin may be a suitable option for osteomyelitis; however, as with many antimicrobials in the setting of osteomyelitis, it is more likely to fail if concomitant source control is not achieved [24].

Low clinical cure rates were also seen for endovascular infections (50\%) owing to one patient with failure and two patients who were lost to follow-up; however, there were no 
Table 3 Summary of non-FDA approved or real-world experience with Dalbavancin studies inadult patients

\begin{tabular}{|c|c|c|c|c|c|c|}
\hline $\begin{array}{l}\text { Citation } \\
\text { (year) }\end{array}$ & Study design & Infection(s) & $\begin{array}{l}\text { Study } \\
\text { population }\end{array}$ & $\begin{array}{l}\text { Dose and } \\
\text { duration }\end{array}$ & $\begin{array}{l}\text { Treatment } \\
\text { response }\end{array}$ & $\begin{array}{l}\text { Adverse drug } \\
\text { events }\end{array}$ \\
\hline $\begin{array}{l}\text { Raad et al. } \\
\qquad(2005) \\
{[12]}\end{array}$ & $\begin{array}{l}\text { Phase } 2 \\
\text { randomized, } \\
\text { controlled, } \\
\text { open label } \\
\text { trial, } 13 \text { sites }\end{array}$ & $\begin{array}{l}\text { Catheter- } \\
\text { related } \\
\text { bloodstream } \\
\text { infections } \\
23 \% \text { MSSA } \\
20 \% \text { MRSA } \\
50 \% \text { CoNS }\end{array}$ & $\begin{array}{l}\text { United States } \\
\text { Initial } \\
\text { treatment } \\
\text { Excluded renal } \\
\text { and liver } \\
\text { dysfunction, } \\
\text { immune } \\
\text { suppression, } \\
\text { complicated } \\
\text { infections } \\
N=26 \text { ( } 23 \text { in } \\
\text { mITT) }\end{array}$ & $\begin{array}{c}1000 \mathrm{mg}, 1 \text { week } \\
\text { later } 500 \mathrm{mg}\end{array}$ & $\begin{array}{l}\text { EOT mITT } \\
20 / 23(87 \%) \\
\text { vs. } \\
\text { vancomycin } \\
14 / 28(50 \%)\end{array}$ & $\begin{array}{l}\text { Hypotension } \\
\text { (21\%), } \\
\text { constipation } \\
(18 \%), \\
\text { diarrhea } \\
(21 \%), \\
\text { anemia } \\
(18 \%)\end{array}$ \\
\hline $\begin{array}{l}\text { Rappo et al. } \\
\qquad \begin{array}{l}(2018) \\
{[13]}\end{array}\end{array}$ & $\begin{array}{l}\text { Phase } 2 \\
\text { randomized, } \\
\text { open-label, } \\
\text { comparator- } \\
\text { controlled, } \\
\text { parallel- } \\
\text { group }\end{array}$ & $\begin{array}{l}\text { Osteomyelitis } \\
\text { (first episode) } \\
54 \% \text { MSSA } \\
6 \% \text { MRSA } \\
20 \% \text { CoNS }\end{array}$ & $\begin{array}{l}\text { Ukraine } \\
\text { Initial } \\
\text { treatment } \\
\text { DM (14\% in } \\
\text { Dalbavancin } \\
\text { group vs. } \\
50 \% \text { SOC) } \\
\text { No SUD } \\
N=70 \text { ( } 67 \\
\text { included due } \\
\text { to follow-up) }\end{array}$ & $\begin{array}{l}1500 \mathrm{mg} \\
2 \text { doses, } 1 \text { week } \\
\text { apart }\end{array}$ & $\begin{array}{c}\text { Clinical cure at } \\
\text { day } 42: 65 / 67 \\
(97 \%) \text { vs. } 7 / 8 \\
\text { (88\%) SOC }\end{array}$ & $\begin{array}{l}\text { None related } \\
\text { to } \\
\text { dalbavancin, } \\
\text { but } 14.3 \% \\
\text { treatment } \\
\text { emergent } \\
\mathrm{AE} \text {, anemia } \\
\text { and bleeding }\end{array}$ \\
\hline $\begin{array}{l}\text { Tobudic } \\
\text { et al. } \\
(2018) \\
{[15]}\end{array}$ & Case series & $\begin{array}{l}\text { Infective } \\
\text { endocarditis: } \\
16 \text { native } \\
\text { valve, } 6 \\
\text { prosthetic } \\
\text { valve, } 5 \\
\text { cardiac } \\
\text { device } \\
29 \% \text { S. aureus } \\
26 \% \\
\text { Streptococcus } \\
13 \% \\
\text { Enterococcus }\end{array}$ & $\begin{array}{l}\text { Austria } \\
\text { Sequential } \\
\text { treatment } \\
N=31 \text { ( } 27 \\
\text { included, due } \\
\text { to missing } \\
\text { data) }\end{array}$ & $\begin{array}{l}1000 \mathrm{mg} \text { loading, } \\
500 \mathrm{mg} \\
\text { maintenance } \\
\text { weekly, Median } \\
\text { duration } 6 \text { weeks } \\
\text { (range } \\
1-30 \text { weeks) }\end{array}$ & $\begin{array}{l}\text { Clinical and } \\
\text { microbiologic } \\
\text { success } \\
6 \text { months } \\
\text { after } \\
\text { completed } \\
\text { therapy } 25 / 27 \\
(93 \%)\end{array}$ & $\begin{array}{l}1 \text { patient with } \\
\text { nausea } \\
1 \text { patient with } \\
2.5 \text {-fold } \\
\text { increase in } \\
\text { creatinine }\end{array}$ \\
\hline
\end{tabular}


Table 3 continued

\begin{tabular}{|c|c|c|c|c|c|c|}
\hline $\begin{array}{l}\text { Citation } \\
\text { (year) }\end{array}$ & Study design & Infection(s) & $\begin{array}{l}\text { Study } \\
\text { population }\end{array}$ & $\begin{array}{l}\text { Dose and } \\
\text { duration }\end{array}$ & $\begin{array}{l}\text { Treatment } \\
\text { response }\end{array}$ & $\begin{array}{l}\text { Adverse drug } \\
\text { events }\end{array}$ \\
\hline $\begin{array}{l}\text { Bouza et al. } \\
\text { (2019) } \\
{[16]}\end{array}$ & $\begin{array}{l}\text { Case series, } 29 \\
\text { sites }\end{array}$ & $\begin{array}{l}\text { Mixed } \\
\text { infections: } \\
\text { PJI, ABSSSI, } \\
\text { OM, IE most } \\
\text { common } \\
35 \% \text { CoNS } \\
23 \% \text { MRSA } \\
\text { 18\% MSSA } \\
\text { 18\% } \\
\text { Enterococcus }\end{array}$ & $\begin{array}{l}\text { Spain } \\
\text { Both initial } \\
\text { and } \\
\text { sequential } \\
\text { treatment } \\
\text { immune } \\
\text { suppressed } \\
(28 \%) \\
\text { DM } 23 \% \\
N=69\end{array}$ & $\begin{array}{l}1500 \mathrm{mg} \\
\text { weekly } \times 2 \text { or } \\
1000 \mathrm{mg} \times 1 \\
\text { followed by } 500 \\
\text { every week, } \\
\text { median duration } \\
3 \text { weeks (range } \\
1-24)\end{array}$ & $\begin{array}{l}\text { Clinical success } \\
\text { at } 30 \text { days } \\
\text { after } \\
\text { completion in } \\
58 / 69(84 \%) \\
\text { (92\% for OM, } \\
86 \% \text { for IE } \\
\text { and } 75 \% \\
\text { CRBSI) } \\
\text { No issues with } \\
\text { follow-up or } \\
\text { missing data } \\
\text { reported }\end{array}$ & $\begin{array}{l}2 \text { patients with } \\
\text { renal } \\
\text { dysfunction; } \\
\text { also rash, } \\
\text { nausea }\end{array}$ \\
\hline $\begin{array}{l}\text { Wunsch } \\
\text { et al. } \\
(2019) \\
{[17]}\end{array}$ & $\begin{array}{l}\text { Case series, } 3 \\
\text { sites }\end{array}$ & $\begin{array}{l}\text { Mixed } \\
\text { infections: } \\
\text { ABSSSI, PJI, } \\
\text { OM, IE, } \\
\text { CRBSI } \\
\text { 33\% CoNS } \\
16 \% \text { MSSA } \\
8 \% \text { MRSA }\end{array}$ & $\begin{array}{l}\text { Austria } \\
\text { Both initial } \\
\text { and } \\
\text { sequential } \\
\text { treatment } \\
N=101 \text { ( } 7 \\
\text { excluded for } \\
\text { follow-up or } \\
\text { serious } \\
\text { ADE) }\end{array}$ & $\begin{array}{l}\text { Variable, } 1500 \mathrm{mg} \\
\text { weekly or } \\
1000 \mathrm{mg} \mathrm{X1}, \\
\text { followed by } \\
500 \mathrm{mg} \text { every } \\
\text { week, median } 3 \\
\text { doses (range } \\
1-32 \text { ), regimens } \\
\text { varied }\end{array}$ & $\begin{array}{l}\text { Clinical success } \\
\text { at } 90 \text { days } \\
\text { after } \\
\text { completion } \\
\text { was } 84 / 94 \\
(89 \%) \\
(92 \% \text { for IE, } \\
85 \% \text { for OM, } \\
93 \% \text { for PJI) }\end{array}$ & $\begin{array}{l}3 \%, \\
\text { anaphylaxis, } \\
\text { fatigue, } \\
\text { vertigo }\end{array}$ \\
\hline $\begin{array}{l}\text { Brysom- } \\
\text { Cohn } \\
\text { et al. } \\
(2019) \\
{[18]}\end{array}$ & Case series & $\begin{array}{l}\text { S. aureus- } \\
\text { related } \\
\text { infections: } \\
\text { IE, OM, } \\
\text { bacteremia, } \\
\text { septic } \\
\text { arthritis } \\
\text { 88\% MRSA }\end{array}$ & $\begin{array}{l}\text { Unites States } \\
\text { Both initial } \\
\text { and } \\
\text { sequential } \\
\text { treatment } \\
\text { PWID } \\
N=32 \text { (17 } \\
\text { completed } \\
\text { course, } 22 \\
\text { where } \\
\text { ultimately } \\
\text { evaluable) }\end{array}$ & $\begin{array}{l}\text { Variable, } 1500 \mathrm{mg} \\
\text { or } 1000 \mathrm{mg} \times 1 \text {, } \\
\text { followed by } \\
500 \mathrm{mg} \text { or } \\
1000 \mathrm{mg} \text { every } \\
\text { week, median } \\
\text { duration } 1 \text { dose } \\
\text { (range } 1-5 \text { ) }\end{array}$ & $\begin{array}{l}\text { Clinical success } \\
\text { at } 1 \text { year } \\
\text { follow-up } \\
18 / 22(81 \%)\end{array}$ & None reported \\
\hline
\end{tabular}


Table 3 continued

\begin{tabular}{|c|c|c|c|c|c|c|}
\hline $\begin{array}{l}\text { Citation } \\
\text { (year) }\end{array}$ & Study design & Infection(s) & $\begin{array}{l}\text { Study } \\
\text { population }\end{array}$ & $\begin{array}{l}\text { Dose and } \\
\text { duration }\end{array}$ & $\begin{array}{l}\text { Treatment } \\
\text { response }\end{array}$ & $\begin{array}{l}\text { Adverse drug } \\
\text { events }\end{array}$ \\
\hline $\begin{array}{l}\text { Morata } \\
\text { et al. } \\
(2019) \\
{[19]}\end{array}$ & $\begin{array}{l}\text { Case series, } 30 \\
\text { sites }\end{array}$ & $\begin{array}{l}\text { Bone and joint } \\
\text { infections } \\
22 \% \text { S. aureus } \\
47 \% \text { CoNS }\end{array}$ & $\begin{array}{l}\text { Spain } \\
\text { Both initial } \\
\text { and } \\
\text { sequential } \\
\text { treatment } \\
\text { DM (16\%) } \\
N=64 \text { ( } 1 \text { lost } \\
\text { to follow-up) }\end{array}$ & $\begin{array}{l}\text { Variable } 1500 \mathrm{mg} \\
\text { or } 1000 \mathrm{mg} \times 1 \text {, } \\
\text { followed by } \\
500 \mathrm{mg} \text { or } \\
1000 \mathrm{mg} \text { every } \\
\text { week, median of } \\
5 \text { doses (IQR } \\
3-7)\end{array}$ & $\begin{array}{l}\text { Clinical success } \\
\text { during or after } \\
\text { treatment } \\
45 / 63(71 \%) \text {, } \\
\text { highest when } \\
\text { implant } \\
\text { removed ( } 76 \% \\
\text { vs. } 65 \%)\end{array}$ & $\begin{array}{l}3 \text { GI distress, } 1 \\
\text { rash, } 1 \\
\text { increase in } \\
\text { creatinine, } \\
\text { none } \\
\text { stopped } \\
\text { because of } \\
\text { AE }\end{array}$ \\
\hline $\begin{array}{l}\text { Almangour } \\
\text { et al. } \\
(2019) \\
{[20]}\end{array}$ & $\begin{array}{l}\text { Case series, } 3 \\
\text { sites }\end{array}$ & $\begin{array}{l}\text { Osteomyelitis } \\
\text { MRSA 48\% } \\
\text { MSSA 39\% }\end{array}$ & $\begin{array}{l}\text { Unites States } \\
\text { Both initial } \\
\text { and } \\
\text { sequential } \\
\text { treatment } \\
\text { DM (32\%) } \\
\text { IVDU (32\%) } \\
N=34 \text { ( } 3 \text { lost } \\
\text { to follow-up) }\end{array}$ & $\begin{array}{l}\text { Variable } 1500 \mathrm{mg} \\
\text { or } 1000 \mathrm{mg} \times 1 \\
\text { followed by } \\
500 \mathrm{mg} \text { or } \\
1000 \mathrm{mg} \text { every } \\
\text { week, median } 3 \\
\text { (range } 1-14 \text { ) }\end{array}$ & $\begin{array}{l}\text { Clinical success } \\
\text { at EOT was } \\
28 / 31(90 \%)\end{array}$ & None reported \\
\hline
\end{tabular}

$E O T$ end of treatment, $S O C$ standard of care, $A D E$ adverse drug event, $A E$ adverse event, $M S S A$ methicillin susceptible $S$. aureus, MRSA methicillin-resistant $S$. aureus, CoNS coagulase negative $S$. aureus, $m I T T$ modified intention to treat, DM diabetes mellitus, $S U D$ substance use disorder, $A E$ adverse event, $P J I$ prosthetic joint infection, $A B S S S I$ acute bacterial skin and skin structure infection, $O M$ osteomyelitis, $I E$ infective endocarditis, CRBSI catheter-related bloodstream infection, $I V D U$ intravenous drug use

relapse infections at day 90. Clinical success was high (93\%) in a comparable study in Italy looking at 27 patients with infective endocarditis [15]. Dalbavancin has been shown to have in vitro activity against biofilms of Staphylococci, and there are data to suggest that dalbavancin may be an effective agent in frequent biofilm infections such as endocarditis [25].

A potential niche for dalbavancin is as an alternative therapeutic option to long-term intravenous access and institutional placement. However, if patients fail to return for maintenance dosing or fail to follow up to assess for clinical response as treatment is ongoing, dalbavancin will fall short in filling this therapeutic niche. Brysom-Cohn et al. focused only on the PWID population and described a high loss to follow-up with only 53\% (17/32) completing treatment, comparable to our SUD population follow-up of $32 \%$ (6/19); however, most of our patients completed the intended treatment course. Nonetheless, these patients had infectious etiologies that traditionally require longterm intravenous antibiotic therapy ( $>2$ weeks) such as osteomyelitis. As such, the lack of follow-up is problematic given the absence of observation for clinical cure, drug toxicities and recrudescent infection that would determine extension, discontinuation or re-initiation of therapy. It is, therefore, important to recognize nonadherence with therapy and loss to followup as significant barriers to successful use of dalbavancin.

SUD and PWID were the most common comorbidities and reason for dalbavancin, 
respectively. PWIDs are an especially vulnerable patient population that carries a high morbidity risk and places a significant burden on the health care system [26]. Most of the patients lost to follow-up had SUD. Despite this setback, 77\% of the clinically evaluable patients with active or history of SUD achieved clinical cure. Thus, dalbavancin offers an alternative treatment option for high-risk patient populations who otherwise are poor candidates for conventional parenteral therapy, provided they followed with treatments. There is much needed improvement in PWID outcomes by applying a multidisciplinary and co-location strategy that has been successfully used in the treatment of coincident opioid use disorder with hepatitis C and/or HIV infection [27].

In this study, dalbavancin mostly functioned as a bridge to discharge patients who otherwise would have stayed in the hospital receiving parenteral antibiotics. When compared with a study evaluating the health care cost and utilization of patients with MRSA infection, the length of stay for our study population was lower (8.0 days versus 22.4 days) [28]. Although no formal cost analysis was done, the data from these two centers suggest that this strategy may potentially help to alleviate some health care costs including costs of hospital stay and prolonged subacute rehabilitation stays. Despite these obvious cost savings, access to dalbavancin for off-label use does present a challenge; obtaining insurance coverage can be time consuming and, at times, may lead to interruption in therapy. This was exemplified by one case for which a patient received one dose of the two planned doses of dalbavancin because of a gap in insurance coverage.

The two cases of nephrotoxicity raise some concerns about renal toxicity with use of dalbavancin. However, conclusions regarding this relationship cannot be made based on these two complicated cases with other contributing causes of AKI. A cumulative effect of doses greater than two and up to seven were otherwise well tolerated. There was no evidence of hepatotoxicity or cytopenias. These study results reinforce that weekly outpatient laboratory monitoring, to include renal function, is recommended.
Based on our experience with dalbavancin at these two different medical centers, we offer criteria for use (Table 4) that have been adapted into our clinical decision support by antimicrobial stewardship and OPAT programs. Dalbavancin offers alternative treatment for select circumstances that should be carefully considered. Infection determinants are required for dalbavancin candidacy, followed by either a

Table 4 Proposed criteria for use for dalbavancin

$\begin{array}{ll}\text { (A) Infection } & \begin{array}{l}\text { 1. Invasive infection with gram- } \\ \text { positive organism that is } \\ \text { microbiologically proven or highly } \\ \text { suspected based on previous } \\ \text { cultures }\end{array} \\ \text { OR }\end{array}$

a This includes: methicillin susceptible $S$. aureus, methicillin-resistant $S$. aureus, Streptococcal spp. and vancomycin-susceptible Enterococcus

b Attention to source control must be made

c Severe cellulitis, failure of high-level oral antibiotics (i.e., linezolid), contraindication to oral options (i.e., concomitant selective serotonin receptor inhibitor and linezolid) and malabsorption/lack of enteral access 
drug determinant (i.e., drug-drug interaction with an alternative) or social determinant (i.e., PWID). By following these criteria for use, inappropriate prescribing of dalbavancin can be limited. Implementation and validation of these proposed criteria for use need to be conducted.

This study has several advantages, including a predominant representation of the PWID and SUD population and the high prevalence of MRSA. We also provide an example of criteria for use that can be adapted by other institutions and summary of the literature. However, due to the small sample size and study design, the overall generalizability is low. There are several other limitations of our study. As a retrospective study, there can be information bias leading to differential misclassification. There is no comparator group, and therefore we are unable to make any conclusions regarding effectiveness against standard of care. Additionally, most patients were on standard of care therapy before starting dalbavancin with the majority completing at least 1 week of antibiotics prior to dalbavancin. Clinical response during that time was not evaluated in our study. Thus, the impact of dalbavancin on clinical cure could not be evaluated separately from the clinical benefits provided by previous antimicrobials. Retention of care was another limitation of our study. Notably, patients at UMMC had higher loss to follow-up at 30 days compared with VAHMCS (42\% versus 12\%). This may be in part because OPAT at UMMC is newly established and has less coordinated care and oversight compared with VAHMCS. The difference in coordinated care and follow-up between the two OPAT programs further highlights the importance of OPAT programs for all long-term parenteral antibiotic therapies including dalbavancin. Multidisciplinary OPAT coordination is an integral component of successful dalbavancin treatment in these high-risk patients.

\section{CONCLUSION}

In conclusion, this study describes two centers' experience with dalbavancin, suggesting a possible role for dalbavancin in the treatment of
non-ABSSSI invasive gram-positive infections. In carefully selected patients and with OPAT oversight, we propose dalbavancin as an alternative to long-term daily intravenous antibiotic therapy in invasive gram-positive infections, but more experience and investigation are needed.

\section{ACKNOWLEDGEMENTS}

Funding. No funding or sponsorship was received for this study or publication of this article.

Authorship. All named authors meet the International Committee of Medical Journal Editors (ICMJE) criteria for authorship for this article, take responsibility for the integrity of the work as a whole and have given their approval for this version to be published.

Prior Presentation. This work was presented previously at ASM Microbe 2018 in Atlanta, GA, 7 June 2018 (poster).

Disclosures. Jacqueline T. Bork, Emily L. Heil, Shanna Berry, Eurides Lopes, Rohini Davé, Bruce L. Gilliam and Anthony Amoroso have nothing to disclose.

Compliance with Ethics Guidelines. The study was approved with a waiver of informed consent in an expedited review by the University of Maryland, Baltimore, Institutional Review Board, which oversees both UMMC and VAMHCS facilities. This study was also performed in accordance with the 1964 Helsinki Declaration and its later amendments or comparable ethical standards.

Open Access. This article is distributed under the terms of the Creative Commons Attribution-NonCommercial 4.0 International License (http://creativecommons.org/licenses/ by-nc/4.0/), which permits any noncommercial use, distribution, and reproduction in any medium, provided you give appropriate credit to the original author(s) and the source, 
provide a link to the Creative Commons license, and indicate if changes were made.

\section{REFERENCES}

1. Noskin GA, Rubin RJ, Schentag JJ, Kluytmans J, Hedblom EC, Smulders M, et al. The burden of Staphylococcus aureus infections on hospitals in the United States. Arch Intern Med. 2005;165:1756-61.

2. Boucher HW, Corey GR. Epidemiology of methicillin-resistant Staphylococcus aureus. Clin Infect Dis. 2008;46(Suppl 5):S344-9.

3. Liu C, Bayer A, Cosgrove SE, Daum RS, Fridkin SK, Gorwitz RJ, et al. Clinical Practice Guidelines by the Infectious Diseases Society of America for the treatment of methicillin-resistant Staphylococcus aureus infections in adults and children. Clin Infect Dis. 2011;52:e18-55.

4. Norris AH, Shrestha NK, Allison GM, Keller SC, Bhavan KP, Zurlo JJ, et al. 2018 Infectious Diseases Society of America Clinical Practice Guideline for the management of outpatient parenteral antimicrobial therapy. Clin Infect Dis. 2019;68:1-4.

5. Ho J, Archuleta S, Sulaiman Z, Fisher D. Safe and successful treatment of intravenous drug users with a peripherally inserted central catheter in an outpatient parenteral antibiotic treatment service. J Antimicrob Chemother. 2010;65:2641-4.

6. Schmidt M, Hearn B, Gabriel M, Spencer M. Predictors of unplanned hospitalization in patients receiving outpatient parenteral antimicrobial therapy across a large integrated healthcare network. Open Forum Infect Dis. 2017;4:ofx086.

7. D'Couto HT, Robbins GK, Ard KL, Wakeman SE, Alves J, Nelson SB. Outcomes according to discharge location for persons who inject drugs receiving outpatient parenteral antimicrobial therapy. Open Forum Infect Dis USA. 2018;5:ofy056.

8. Zhanel GG, Trapp S, Gin AS, DeCorby M, LagacéWiens PRS, Rubinstein E, et al. Dalbavancin and telavancin: novel lipoglycopeptides for the treatment of gram-positive infections. Expert Rev AntiInfect Ther. 2008;6:67-81.

9. Barber K, Tirmizi A, Finley R. Dalbavancin use for the treatment of methicillin-resistant Staphylococcus aureus pneumonia. J Pharmacol Pharmacother. 2017;8:77-9.

10. Cho JC, Estrada SJ, Beltran AJ, Revuelta MP. Treatment of methicillin-sensitive Staphylococcus aureus bacteremia secondary to septic phlebitis using dalbavancin. J Clin Pharm Ther. 2015;40:604-6.

11. Barnea Y, Lerner A, Aizic A, Navon-Venezia S, Rachi E, Dunne MW, et al. Efficacy of dalbavancin in the treatment of MRSA rat sternal osteomyelitis with mediastinitis. J Antimicrob Chemother. 2016;71:460-3.

12. Raad I, Darouiche R, Vazquez J, Lentnek A, Hachem $\mathrm{R}$, Hanna $\mathrm{H}$, et al. Efficacy and safety of weekly dalbavancin therapy for catheter-related bloodstream infection caused by gram-positive pathogens. Clin Infect Dis. 2005;40:374-80.

13. Rappo U, Puttagunta S, Shevchenko V, Shevchenko A, Jandourek A, Gonzalez PL, et al. Dalbavancin for the treatment of osteomyelitis in adult patients: a randomized clinical trial of efficacy and safety. Open Forum Infect Dis. 2019;6:ofy331.

14. Molina Collada J, Rico Nieto A, Díaz de Bustamante Ussia M, Balsa Criado A. Artritis séptica de rodilla nativa por Corynebacterium striatum. Reumatol Clín. 2017;14:301-2.

15. Tobudic S, Forstner C, Burgmann $H$, Lagler $H$, Ramharter M, Steininger C, et al. Dalbavancin as primary and sequential treatment for gram-positive infective endocarditis: 2-year experience at the General Hospital of Vienna. Clin Infect Dis. 2018;67:795-8.

16. Bouza E, Valerio M, Soriano A, Morata L, Carus EG, Rodríguez-González C, et al. Dalbavancin in the treatment of different gram-positive infections: a real-life experience. Int $\mathrm{J}$ Antimicrob Agents. 2018;51:571-7.

17. Wunsch S, Krause R, Valentin T, Prattes J, Janata O, Lenger A, et al. Multicenter clinical experience of real life Dalbavancin use in gram-positive infections. Int J Infect Dis. 2019;81:210-4.

18. Bryson-Cahn C, Beieler AM, Chan JD, Harrington $\mathrm{RD}$, Dhanireddy S. Dalbavancin as secondary therapy for serious Staphylococcus aureus infections in a vulnerable patient population. Open Forum Infect Dis. 2019 [cited 2019 Mar 6]; 6. Available from: https://academic.oup.com/ofid/article/6/2/ofz028/ 5304406 .

19. Morata L, Cobo J, Fernández-Sampedro M, Vasco PG, Ruano E, Lora-Tamayo J, et al. Safety and efficacy of prolonged use of dalbavancin in bone and joint infections. Antimicrob Agents Chemother. 2019;AAC.02280-18, aac;AAC.02280-18v1.

20. Almangour TA, Perry GK, Terriff CM, Alhifany AA, Kaye KS. Dalbavancin for the management of grampositive osteomyelitis: effectiveness and potential utility. Diagn Microbiol Infect Dis. 2019;93:213-8. 
21. Gonzalez-Ruiz A, Gargalianos-Kakolyris P, Timerman A, Sarma J, José González Ramallo V, Bouylout $\mathrm{K}$, et al. Daptomycin in the clinical setting: 8-year experience with gram-positive bacterial infections from the EU-CORE(SM) registry. Adv Ther. 2015;32:496-509.

22. Steele JM, Seabury RW, Hale CM, Mogle BT. Unsuccessful treatment of methicillin-resistant Staphylococcus aureus endocarditis with dalbavancin. J Clin Pharm Ther. 2018;43:101-3.

23. Kim A, Kuti JL, Nicolau DP. Review of dalbavancin, a novel semisynthetic lipoglycopeptide. Expert Opin Investig Drugs. 2007;16:717-33.

24. Spellberg B, Lipsky BA. Systemic antibiotic therapy for chronic osteomyelitis in adults. Clin Infect Dis. 2012;54:393-407.

25. Fernández J, Greenwood-Quaintance KE, Patel R. In vitro activity of dalbavancin against biofilms of staphylococci isolated from prosthetic joint infections. Diagn Microbiol Infect Dis. 2016;85:449-51.

26. Collier MG, Doshani M, Asher A. Using population based hospitalization data to monitor increases in conditions causing morbidity among persons who inject drugs. J Community Health. 2018;43:598-603.

27. Treloar C, Rance J, Grebely J, Dore GJ. Client and staff experiences of a co-located service for hepatitis $\mathrm{C}$ care in opioid substitution treatment settings in New South Wales, Australia. Drug and Alcohol Depend. 2013;133:529-34.

28. Nelson RE, Jones M, Liu CF, Samore MH, Evans ME, Graves N, et al. The impact of healthcare-associated methicillin-resistant Staphylococcus aureus infections on post-discharge healthcare costs and utilization. Infect Control Hosp Epidemiol. 2015;36:534-42. 